\title{
Influence Of Demographic Factors On Memory And Attention (Cognitive Ability) Among Hearing-Impaired
}

\author{
Ummi Habibah Abd Rani ${ }^{1, *}$ and Najib Ahmad Marzuki ${ }^{1}$ \\ ${ }^{1}$ School of Applied Psychology, Social Work and Policy, University Utara Malaysia, Malaysia
}

\begin{abstract}
The aim of this study was to examine the influence of demographic factors on cognitive ability (memory and attention) among hearing-impaired students. Data from 163 hearing-impaired students were collected using simple random sampling at five polytechnics in Malaysia. The Cambridge Neuropsychological Test Automated Battery (CANTAB) software were utilised to examine cognitive ability (memory and attention). Demographic factors consist of gender, hearing aid usage and parents' hearing status. The results revealed that attention and memory differed according to hearing aid usage and parent's status of hearing. No significant differences were found for memory and attention according to hearing-impaired gender. The findings of this study will enable the education authority to direct these special students in a way that best suits the institution and students goals.
\end{abstract}

\section{Introduction}

Hearing-impaired can be related to impediment to access an information in educational experiences. The perception of hearing-impaired students as concrete, literal thinkers has now been replaced by a better understanding of the interactions of language and intellectual development in hearing-impaired students. Hearing-impaired was linked with significant delays in spoken language [1]. The language development seems to be specifically influence learning process which is linked to general cognitive process of association, attention and memory. However, it was identify that the absence of auditory stimulation and language delay appear to affect neurocognitive domains, such as memory, attention, auditory and inhibition [1].

According to Myklebust, individuals with hearing impairment were cognitively different and interpreted as having limited memory capacities and languagerelated cognitive deficits. In mainstream programs with hearing-impaired students in segregated (residential or separate) programs often assumed that all other things are equal. But all other things are seldom equal when it comes to hearing-impaired. Most investigations of this issue have not taken into account the intellectual abilities, language fluencies, or social skills of hearingimpaired students. Such findings should not be taken to imply that hearing-impaired students will always have learning difficulties. Instead, they should be seen as emphasizing the need for a more complete understanding of hearing-impaired students' cognitive ability such as attention and memory if we are to foster educational success [2].

Individuals with Disabilities Education Act suggest the assessment of cognitive abilities is essential for differential diagnosis in educational settings such as identifying eligibility for special education programs in large part on the basis of cognitive abilities [3].

Based on the literature, memory and attention of hearing-impaired students were influenced by demographic factors. Apparently, the hearing-impaired cognitive ability can influence various aspects of life in some individuals, their families and society. Research focusing on specific aspects of cognitive aspect, such as memory and attention and influence of demographic factors have yielded contradictory results specifically among hearing-impaired in Malaysia. Therefore, accomplishing this study expands the knowledge of memory and attention (cognitive ability) as well as hearing disabilities and special education study in Malaysia.

In this study, cognitive ability was defined based on Horn and Noll, describe cognitive ability as intellectual human ability to accomplish and manage something complex through mental analysis [4]. The attention and memory are the components of cognitive ability. Throughout this paper, the term attention refers to how well students can focus when faced with internal distractions such as mind wandering and boredom; while students' cognitive ability in memory refers to how well students utilized their memory when faced with external distractions. Hearing-impaired mentioned to people with limited hearing and deafness stated to the audiological condition of not hearing [5]. According to World Health Organization [WHO], hearing Impairment is defined as an absolute or partial loss of the capacity to hear out of one or two ears. The degree of impairment can be mild, moderate, severe or 
profound [6]. Whereas, a hearing aid is a device that amplifies and customizes incoming sound signals to meet specific requirements of each hearing impaired.

Studies done found no significant gender difference in general intelligence [7-9]. Moreover, reports of male and females not differ in reaction time [10]. There are, however males better cognitive ability performance [11].

There also appears to be a gender difference in episodic memory with females performing better in most tasks, although this area has not been the subject of meta-analysis. The finding on the recall test is consistent with previous research showing better female performance on long term memory tasks [12].

Hearing-impaired people, in contrast, have been said to rely heavily on visual-spatial short-term memory codes [2]. The most frequently cited support for the notion that hearing-impaired individuals tend to use visual short-term memory codes comes from a series of studies conducted by Parasnis reports that there were no gender differences in cognitive ability of hearing-impaired people [13].

The origins of these cognitive gender differences are still not fully understood [9]. Although there is no doubt that sex hormones and sexual brain dimorphisms contribute to sex differences in specific cognitive abilities, it is also clear that social priming, and especially gender stereotypes can significantly affect male's and female's cognitive performance [14-15]. In fact, gender stereotypes might be a central variable in environmental influences on sex differences in intelligence [9].

Gatehouse show a significant interactions between hearing impairment and cognitive ability, and the extent to which, when tested unaided, listeners can derive and gain advantage from temporal structure [18]. This is similar with Mulrow study who found changes in cognitive aspect among aided hearingimpaired [16].

According to Marschark, hearing-impaired who's born into a family with hearing-impaired members, for example, is often exposed to sign language early in life, and hearing-impairment is not viewed as negatively as it might be in a family with no such history [17].

Studies show that hearing-impaired born in hearing-impaired families and growing up in an environment where the conversation is naturally dependent on visual have an advantage compared to those who raised by normal hearing parents [18]. Accordingly, hearing-impaired students of hearingimpaired parents may be able to attain higher levels of cognitive activities.

One might expect that hearing-impaired of hearingimpaired parents would perform comparably to hearing peers on most cognitive tasks, but these expectations are not met with any consistencies. More research is needed with larger numbers of students before conclusive findings can be obtained. The lack of any causal link between language delays and cognitive abilities in hearing-impaired indicate that there are undiscovered factors that influence evaluations of cognitive development in hearing-impaired students.

\section{Methods}

\subsection{Research Design}

The study followed a prospective cross-sectional design for examine the influence of demographic factors on memory and attention who are hearingimpaired students. The main reason for choosing a quantitative method for the cross-sectional correlational survey design was due to the required degree of generalization of results. The rationale for this research stems from the fact that the design allows researchers to examine various variables.

\subsection{Participants}

Participants for this study involved the students with hearing-impaired from five polytechnics in Malaysia. The participating students were identified as students with hearing disabilities by their polytechnic and are currently receiving special education services at their polytechnic. The participants consisted of both male and female students. For this study, researcher select the participants through simple random sampling technique. A random size of 163 participants was taken based on Krejcie and Morgan table [19], from a population size of 198 .

\subsection{Instrument}

The cognitive ability (memory and attention) was assessed by the cognitive test battery. The software program called Cambridge Neuropsychological Test Automated Battery (CANTAB) [20], which provide an effective method of cognitive ability assessment, was utilised to test the cognitive ability of hearing-impaired students at Malaysian Polytechnics. CANTAB has been specifically designed for assessing the cognitive abilities from animals to humans. Application of test batteries, including diagnosis, cognitive development and occupational work is a "law" that was highlighted by CANTAB. The CANTAB is a computed nonverbal battery of visually presented neuropsychological tests. The test were administered on a touch-sensitive computer screen and were completed by the participants.

\subsection{Data Analysis}

The Statistical Package for the Social Sciences (SPSS) version 21 was performed to analyse the data. The independent $\mathrm{t}$-test was conducted to investigate the differences in mean between (attention and memory) cognitive ability and demographic factors. 


\section{Results and Discussion}

\subsection{Differences of attention and memory based on gender}

The result showed that there were no significant differences of memory with $[t=.94, p>.05]$ and attention $[t=.34, p>.05]$ between both gender. Referring to table 1, there were no significant differences of attention and memory mean between male and female hearing-impaired.

Table 1: Attention and memory between gender

\begin{tabular}{llllll}
\hline $\begin{array}{l}\text { Cognitive } \\
\text { ability }\end{array}$ & Gender & $\mathrm{N}$ & Mean & SD & $\mathrm{t}$ \\
\hline \multirow{2}{*}{ Attention } & Male & 79 & 3.78 & 1.09 & .94 \\
& Female & 84 & 3.94 & 1.00 & \\
\hline \multirow{2}{*}{ Memory } & Male & 79 & 3.22 & 1.11 & .34 \\
& Female & 84 & 3.15 & 1.12 & \\
\hline
\end{tabular}

As can be seen, male and female hearing-impaired in polytechnics appeared to demonstrate attention and memory irrespective of the gender status. This discovery supports studies that found that no significance gender differences in cognitive ability [78] and attention [10]. Nevertheless, the current findings in contrast with Wai and Lincoln,which found males tend to have higher cognitive ability [21].

\subsection{Differences of attention and memory based on hearing aid usage}

As demonstrated in table 2 , there were significant differences of memory with $[t=4.76, p<.05]$ and attention $[t=5.02, p<.05]$ between hearing aid usage. Results indicating that there were significant differences of attention and memory between hearing aid usages of respondents.

Table 2: Attention and memory between hearing aid usage

\begin{tabular}{|c|c|c|c|c|c|}
\hline Cognitive ability & $\begin{array}{l}\text { Hearing aid } \\
\text { usage }\end{array}$ & $\mathrm{N}$ & Mean & $\mathrm{SD}$ & $\mathrm{t}$ \\
\hline \multirow{2}{*}{ Attention } & Yes & 60 & 4.24 & 1.55 & \multirow[t]{2}{*}{$4.76^{*}$} \\
\hline & No & 103 & 3.23 & 0.79 & \\
\hline \multirow{2}{*}{ Memory } & Yes & 60 & 3.67 & 1.55 & \multirow[t]{2}{*}{$5.02 *$} \\
\hline & No & 103 & 2.54 & 1.27 & \\
\hline
\end{tabular}

With reference to the table, it appears that memory and attention of hearing-impaired in polytechnics differed based on hearing aid usage. The result is supported by Gatehouse, who found that cognitive ability of aid and unaided hearing-impaired differed [22]. In this study, the significant difference achieved by students may be due to the ability of hearingimpaired with hearing aid to speak, hear and communicate better than unaided hearing-impaired. Thus, it will contribute to enhance their attention and memory during the learning process. According to Zand and Pierce, hearing aids provide sustained benefits for individuals with hearing impairment [23].

\subsection{Differences of attention and memory based on parents' hearing status}

The findings showed that there were significant difference of memory with $[t=4.07, p<.05]$ and attention [t=3.99, $p<.05]$ between parent's hearing status. The outcome in table 1 revealed that there were significant differences of attention and memory between normal hearing parent and hearing-impaired parent. 
Table 3: Attention and memory between parent's hearing status

\begin{tabular}{cccccc}
\hline $\begin{array}{l}\text { Cognitive } \\
\text { ability }\end{array}$ & $\begin{array}{c}\text { Parents' hearing } \\
\text { status }\end{array}$ & $\mathrm{N}$ & Mean & $\mathrm{SD}$ & $\mathrm{t}$ \\
\hline \multirow{2}{*}{ Attention } & $\begin{array}{l}\text { Normal } \\
\text { Hearing } \\
\text { impaired }\end{array}$ & 123 & 3.39 & 1.22 & $4.07^{*}$ \\
& Normal & 123 & 2.67 & 1.45 & \multirow{2}{*}{$3.99^{*}$} \\
\hline \multirow{2}{*}{ Memory } & $\begin{array}{l}\text { Hearing } \\
\text { impaired }\end{array}$ & 40 & 3.70 & 1.34 & \\
\hline
\end{tabular}

Notes: ${ }^{*} p<.05$

The results showed that parents' hearing status based on attention and memory differed between normal hearing parent and hearing-impaired parent. As reported by Tyrose, parent hearing status are associated with the cognitive ability. In this study, it can be assumed that the cognitive ability are heightened by communication style of hearing-impaired parent such as using sign language, hand and body movement which involve visual movement and memory coding [24]. According to Marschark, sign language contribute to cognitive development and visual imagery [2].

\section{Conclusion}

In conclusion, attention and memory differed according to hearing aid usage and parent's status of hearing. The study also found that no significant differences for memory and attention according to hearing-impaired gender. Thus, a few suggestions are recommended to increase the memory and attention of hearing-impaired students. The ability to profit from both formal and informal instruction at education system requires that students have skills in areas such as attention, memorizing and have a positive attitude toward learning. More educators are needed to serve as role models and to be fluent communicators with students who are hearing-impaired. It can match accessible teaching strategies and materials to the needs of hearing-impaired learners in order to provide them with fair and appropriate education. The exposure to normal hearing peers and educators to sign language skills program may leads to a supportive environment and may influence attention and memory of hearingimpaired students. Relevant education authorities should take necessary steps in improving the hearing impaired students' attention and memory (cognitive ability).

\section{References}

1. D. Koo, K. Crain, C. LaSasso, G.F. Eden, Ann. N.Y. Aca. Sc., 1145, 83-99, doi: 10.1196/annals.1416.025 (2008)

2. M. Marschark, C. Morrison, J. Lukomski, G. Borgna, C. Convertino, Learn. Indv. Diff., 25, 156-162.

doi: http://doi.org/10.1016/j.lindif.2013.02.006 (2013)
3. Individuals with Disabilities Education Act Amendments

(1997).http://www.ed.gov/offices/OSERS/IDEA/i ndex.html. (2014)

4. J. L. Horn, J. A. Noll, Contemporary intellectual assessment: Theories, tests, and issues, (New York: Guilford, 53-91, 1997)

5. National association of the deaf., The Guide for Deaf and Hard of Hearing People (National Association of the Deaf), http://ebooklibrary.space/?book $=1563686449, \quad 6$, (Washington, DC: Gallaudet University Press, 2015)

6. World Health Organization, Deafness and hearing impairment. http://www.who .int/mediacentre/factsheets/fs3 00/en/index .html (2006)

7. A. Saggino, M. Balsamo, A. Grieco, M. R. Cerbone, N. N. Raviele, N.N. Perce. Mot. Skills, 98,840-848. doi:10.2466/pms.98.3.840-848 (2006)

8. M. Burgaleta, K. Head, J. Álvarez-Linera, K. Martínez, S. Escorial, R. Haier, et al., Intel, 40, 60-68. doi.org/10.1016/j.intell.2011.10.006. (2012)

9. D.G. Halpern, M.L. LaMay, Edu. Psycho. Rev, 12, 229-246

https://www.academia.edu/2758826/The_Smarter Sex_A_Critical_Review_of_Sex_Differences_in_I ntelligence $(20 \overline{0} 0)$

10. D. Reilly, D. Neumann, G. Andrews, Intel, 54, 147-158. doi: 10.1016/j.intell.2015.12.004 (2016)

11. L. H. Summers, Remarks at NBER Conference on Diversifying the Science \& Engineering Workforce, (http://www.harvard.edu/president/ speeches/summers_2005/nber.php (Cambridge, M.A., 2005)

12. C. Flores-Mendoza, K.F. Widaman, H. Rindermann, R. Primi, M. Mansur-Alves, C. C. Pena, Intel, 41, 70-84, doi: http://dx.doi.org/10.1016/j.intell.2012.11.002 (2013)

13. I. Parasnis, Cultural and Language Diversity and the Deaf Experience, 79-98, (Cambridge: Cambridge University Press, 1998) 
14. M. Hausmann, D. Schoofs, H. E. S. Rosenthal, K. Jordan, Psychoneuro., 34, 389-401, doi:10.1016/j.psyneuen.2008.09.019 (2009)

15. M. Hirnstein, N. Freund, M. Hausmann, Zeits. Psycho., 220,70-77. doi: 10.1027/21512604/a000098 (2012)

16. C. D. Mulrow, M. R. Tuley, C. Aguilar, J. Speech Hear. Res., 35, 1402-1405, doi:10.1044/jshr.3506.1402 (1992)

17. M. Marschark, H. G. Lang, J. A. Albertini, Educating Deaf Students: From Research to Practice, (Oxford: Oxford University Press, 2002)

18. E. Jambor, M. Elliott, M., Stud. D. Edu., 10(1), 63-81. Retrieved 18 March,, 2014, doi:10.1093/deafed/eni004 (2005)

19. R. V. Krejcie, D. W. Morgan, Determining sample size for research activities. Educational and Psychological Measurement. https://opa.uprrp.edu/InvInsDocs/KrejcieandMorg an.pdf (1970)

20. CANTAB:Cognitive Test Neuropsychological Test Automated Batteries, 5, (England: Cambridge Cognition Ltd, 2015)

21. J. Wai, D. Lincold, Intel, 54, 1-32. doi.org/10.1016/j.intell.2015.11.002 (2016)

22. S.J. Zand, K. J. Pierce, K. (Eds.)., Resilience in deaf children: Adaption through emerging adulthood, (New York, Springer, 2011)

23. H. Dillon, Inter. J. Audio., 42, S77-S85. doi:10.3109/14992020309074627. (2003)

24. M. P. Tayrose, The Developmental Organization of Cognitive Abilities of Deaf and Hard of Hearing (D/HOH) People as Compared to those who are Normal Hearing http://repository.lib.ncsu.edu/ir/bitstream/1840.16/ 6766/1/etd.pdf (North Carolina State University Raleigh, North Carolina 2011) 